\title{
Induction of c-fos mRNA by Kindled Seizures: Complex Relationship with Neuronal Burst Firing
}

\author{
David M. Labiner, ${ }^{1,4}$ Linda S. Butler, ${ }^{1,4}$ Zhen Cao,, David A. Hosford, ${ }^{1,4}$ Cheolsu Shin, ${ }^{1,4}$ and James 0. \\ McNamara ${ }^{1,2,3,4}$ \\ Departments of ${ }^{~ M e d i c i n e ~(N e u r o l o g y), ~}{ }^{2}$ Neurobiology, and ${ }^{3}$ Pharmacology, Duke University Medical Center, and ${ }^{4} E p i l e p s y$ \\ Research Laboratory, Department of Veterans Affairs Medical Center, Durham, North Carolina 27710
}

Expression of the immediate-early gene c-fos has been advanced as a marker of neuronal activity in the adult nervous system. We sought to test the validity of c-fos mRNA expression as a marker of neuronal activity during seizures and to elucidate specific neurotransmitter receptors whose activation was necessary for seizure-evoked c-fos mRNA expression. We correlated c-fos mRNA expression, measured with in situhybridization, with kindled seizure-induced firing of hippocampal dentate granule cells or substantia nigra pars compacta and pars reticulata neurons. We found that the occurrence of seizure-evoked synchronous action potentials during the seizure exhibited a perfect qualitative correlation with the presence of c-fos mRNA expression in the granule cells $\mathbf{3 0}$ min following the seizure (Fisher's exact test, $p=0.002$ ). However, there was no quantitative correlation between the number of seizure-induced population action potentials and the magnitude of c-fos mRNA expression in the granule cells. In the substantia nigra, where neuronal populations have previously been demonstrated to exhibit synchronous firing during kindled seizures, no induction of C-fos mRNA was detected in either pars compacta or pars reticulata. Pretreatment with antagonists of the NMDA subtype of glutamate receptor selectively and markedly decreased seizure-induced c-fos mRNA expression in the dentate granule cells, despite increasing the number of granule cell population action potentials.

These findings illustrate the complexity of the relationship between c-fos induction and neuronal burst firing during kindled seizures. We caution that c-fos mRNA expression is not a simple marker of neuronal activity. We suggest that seizure-induction of c-fos mRNA expression may correlate better with sustained neuronal depolarization and subsequent rise of intracellular calcium evoked by multiple factors, one of which is NMDA receptor activation.

IKey words: c-fos, neuronal activity, kindling, epilepsy, seizure, NMDA, dentate granule cells, substantia nigra]

\footnotetext{
Received May 22, 1992; revised July 31, 1992; accepted Aug. 19, 1992.

We thank Drs. Douglas Bonhaus, Raymond Dingledine, James Eberwine, and J. Victor Nadler for helpful discussions. We are grateful to Lewis Kigsbee for the technical assistance and to Drs. J. I. Morgan and T. Curran (Roche Institute of Molecular Biology, Nutley, NJ) for providing the c-fos cDNA probe used in preliminary studies. This study was supporled in part by grants from the National Institutes of Health (NS17771, NS25608, NS01232, NS08524) and the Veterans Administration.

Correspondence should be addressed to James O. McNamara, M.D., Dukc University Medical Center, 401 Bryan Building, Box 3676, Durham, NC 27710. Copyright (C) 1993 Society for Neuroscience $0270-6474 / 93 / 130744-08 \$ 05.00 / 0$
}

c-fos, an immediate-early gene, undergoes dramatic and transient expression in response to a diversity of stimuli in vitro (Curran and Morgan, 1987; Morgan and Curran, 1989). The striking activation of c-fos expression in neurons by depolarization in vitro (Morgan and Curran, 1986) and by seizures in vivo (Morgan et al., 1987) led to its proposed use as a marker of neuronal activity in the mammalian nervous system (Sagar et al., 1988).

Seizures are characterized by a specific pattern of neuronal activity, namely, the synchronous firing, or burst firing, of populations of neurons in discrete pathways of the nervous system. The availability of a sensitive and reliable histochemical marker of this pattern of neuronal activity with cellular resolution would permit elucidating the networks activated during a seizure, and in turn facilitate pharmacologic and surgical efforts aimed at controlling medically refractory seizures.

Despite its attractiveness, the validity of c-fos expression as a marker of neuronal activity during a seizure has not been directly tested. The goals of this work were twofold: (1) to test the validity of c-fos mRNA expression as a marker of seizureinduced neuronal activity by correlating the activity of distinct populations of neurons during a seizure with c-fos mRNA expression induced in these neurons by a seizure, and (2) to elucidate specific neurotransmitter receptors whose activation is required for seizure induction of $\mathrm{c}$-fos $\mathrm{mRNA}$ expression in these neurons.

We examined the seizure-evoked neuronal activity of the hippocampal dentate granule cells with field potential recordings in vivo, and we mcasured c-fos mRNA cxpression with in situ hybridization. The dentate granule cells were chosen because of the robust effect of seizures on c-fos expression in this group of neurons (Morgan et al., 1987) and because the population field potentials generated by the dentate granule cells have been extensively characterized electrophysiologically (Andersen et al., 1971; Lomo, 1971). We also examined c-fos mRNA expression in the substantia nigra, a nucleus in which burst-firing neuronal activity during kindled seizures has been previously characterized with single- and multiple-unit activity (Bonhaus et al., 1986, 1991).

\section{Materials and Methods}

Preparation and kindling of animals for correlation of dentate field potentials and $c$-fos expression

Adult malc Sprague-Dawley rats (Charles River, Wilmington, DE) weighing at least $250 \mathrm{gm}$ underwent stereotaxic implantation of a bipolar stimulating/recording electrode in the right amygdala under pentobar- 
bital ancsthesia using the following coordinates with instrument zero as reference: $\mathrm{AP}+3.0 \mathrm{~mm}$, ML $4.8 \mathrm{~mm}$, DV $2.3 \mathrm{~mm}$ below dura. A concentric bipolar electrode used for recording electroencephalographic activity (EEG) and dentate field potentials was placed in the dentate hilus of the left dorsal hippocampus. Characteristic extracellular field potentials of dentate granule cells following stimulation of the left angular bundle were used to optimize electrode placements as described previously (Shin et al., 1987). Following a postoperative recovery period of at least $7 \mathrm{~d}$, stimulus trains $(500 \mu \mathrm{A}, 1 \mathrm{msec}$ biphasic rectangular pulses, $60 \mathrm{~Hz}, 1 \mathrm{sec}$ duration) were administered once daily, $5 \mathrm{~d}$ per week, through the amygdala electrode until two class 5 seizures were evoked. Following a 1 week seizure-free period, single shocks were administered through the stimulating electrode in the left angular bundle to verify that the recordings of the left dentate exhibited the pattern typical of the field EPSP and population action potentials of the dentatc granule cells (Shin et al., 1987). Thereupon, a stimulus train was administered through the amygdala electrode and a class 5 kindled seizure was evoked; dentate field potentials were recorded during the seizure Each animal was killed $30 \mathrm{~min}$ following the seizure and brain sections were prepared for in situ hybridization as described below.

During the kindled seizure, electrographic seizure [afterdischarge (AD)] was recorded from the bipolar electrode in the right amygdala and from the concentric bipolar electrode in the contralateral (left) dentate hilus field potentials were also recorded in the left dentate. These events were recorded on a Vetter-modified Panasonic video cassette recorder (model 420B). The analog recording was digitized and analyzed by Computerscope (R.C. Electronics, Santa Barbara, CA). The recordings were analyzed by counting the number of population action potentials ("population spikes") and by measuring the amplitude of the largest population spike during the seizure. The presence or absence of population action potentials was ascertained without prior knowledge of $\mathrm{c}-f \circ s$ expression.

\section{Preparation and kindling of animals for analysis of drug effects on seizure-evoked c-fos expression}

To simplify investigation of drug on seizure-induced c-fos mRNA expression, kindled seizures evoked by hippocampal stimulation wcre studied because these are associated with a massive, bilateral induction of c-fos mRNA expression in the hippocampal dentate granule cells in every animal. To prepare these animals, a stainless steel bipolar stimulating/recording electrode was implanted in the right dorsal hippocampus under pentobarbital anesthesia $(50 \mathrm{mg} / \mathrm{kg}$, i.p.); the stereotaxic coordinates, using bregma as a reference, were AP $-3.2, \mathrm{ML}+2.1$, and DV -3.1 from dura (nose bar at 0 ). An additional electrode was secured to skull screws for use as a reference in EEG recordings. After a postoperative recovery of at least 1 week, animals were stimulated twice daily (l sec trains of $1 \mathrm{msec}$ biphasic rectangular pulses delivered at a frequency of $60 \mathrm{~Hz}$ ) with a current intensity sufficient to evoke an $\mathrm{AD}$. Stimulations were administered until the animals exhibited at least six class 4 or 5 seizures (Racine, 1972), the last three being consecutive. The generalized seizure threshold was subsequently determined by oncedaily stimulations as previously described (McNamara et al., 1984), except that the current intensities used were $30 \mu \mathrm{A}$ above and below the threshold. After a stimulation-free interval of at least 1 week, animals were used in one of the experimental protocols described below.

Kindled animals received an intraperitoneal injection of either vehicle or drug prior to a stimulus-evoked seizure. The stimulations were 30 $\mu \mathrm{A}$ above the generalized seizure threshold and $2 \mathrm{sec}$ in duration. Animals were killed by decapitation $30 \mathrm{~min}$ after the evoked seizure; the brains were rapidly dissected and frozen in 2-methylbutane in a dry ice/methanol bath.

\section{Determination of drug effects on kindled seizure-evoked granule cell population action potentials}

To characterize drug effects on the electrophysiologic events in the right dentate gyrus during seizures evoked by left hippocampal stimulation, additional animals were prepared as follows. A bipolar electrode to be used for kindling stimulations was implanted in the left hippocampus using stereotaxic guidance as above. In addition, a concentric bipolar electrode used for recording EEG and dentate granule cell field potentials was placed in the dentate hilus of the right dorsal hippocampus using elcctrophysiologic guidance with stimulation of the right angular bundle as described previously (Shin et al., 1987). These animals received kindling stimulations and their seizure thresholds were determined as de- scribed for the experiments examining drug effects. In order for each animal to serve as its own control, seizures were evoked after treatment with either vehicle $\left(\mathrm{H}_{2} \mathrm{O}, 1.0 \mathrm{ml} / \mathrm{kg}\right)$ or $\mathrm{MK}-801(1.0 \mathrm{mg} / \mathrm{kg})$. Two of the animals initially received vehicle, and the other two initially received MK-801. After receiving the initial treatment and a seizure, the generalized seizure threshold was determined again. Following a 1 week stimulation-free period, the second treatment was administered. Prior to each seizure the field potential response in the right dentate evoked by right angular bundle stimulation $(0.1 \mathrm{~Hz})$ was recorded as previously described (Shin et al., 1987). EEG and dentate field potentials were recorded and analyzed without knowledge of drug treatments; the methods were as described in the experiments correlating seizure-induced c-fos expression with granule cell activity.

\section{$c$-fos in situ hybridization}

Oligonucleotide probes. The oligonucleotide sequence comprised 50 bases, $50 \%$ of which were deoxyguanosine and deoxycytidine. The sequence utilized, nucleotides 270-319 of rat c-fos (Curran et al., 1987), was not significantly homologous to other sequences cataloged in the rodent gene bank library accessed through the Baylor College of Medicine Molecular Biology Information Resource. Radiolabeled oligonucleotide probes were prepared with a $3^{\prime}$-terminal transferase reaction and ${ }^{32} \mathrm{P}-\mathrm{dATP}(6000$ Ci/mmol; Du Pont-New England Nuclear, Wilmington, DE) to yield a specific activity of $1.6-6.0 \times 10^{9} \mathrm{dpm} / \mu \mathrm{g}\left(1-4 \mathrm{~mol}\right.$ of ${ }^{32} \mathrm{P}-\mathrm{dATP}$ per mole of oligonucleotide). The c-fos oligonucleotide sequence was validated by demonstrating that it hybridized to a single 2.2 kilobase band in a Northern blot containing RNA extracted from rat hippocampus following an AD evoked by angular bundle stimulation; a nick-translated rat c-fos cDNA probe hybridized to the same band.

In situ hybridization. In situ hybridization was performed with 10$\mu \mathrm{m}$-thick frozen sections that were thaw-mounted on autoclaved gelatincoated slides. The slide-mounted sections were fixed for $30 \mathrm{~min}$ at room temperature in phosphate-buffered saline (PBS; $10 \mathrm{~mm} \mathrm{NaCl}, 1.6 \mathrm{~mm}$ $\mathrm{NaH}_{2} \mathrm{PO}_{4}, 8.4 \mathrm{mM} \mathrm{Na} 2 \mathrm{HPO}_{4}, \mathrm{pH} 7.0$ ) conlaining 4\% paraformaldehyde, followed by graded ethanol dehydration $(70 \%$ for $5 \mathrm{~min}, 95 \%$ for $5 \mathrm{~min}$, $100 \%$ for $5 \mathrm{~min}$ ). The sections were prehybridized for $4 \mathrm{hr}$ at $37^{\circ} \mathrm{C}$ in a solution containing $50 \%$ formamide (Bethesda Research Labs, Gaithersburg, MD), $2 \times$ NTE ( $300 \mathrm{~mm} \mathrm{NaCl}, 10 \mathrm{~mm}$ Tris, $1 \mathrm{~mm}$ EDTA, pH 8.0), $1 \times$ Denhardt's solution, $500 \mu \mathrm{g} / \mathrm{ml}$ yeast tRNA (Sigma), $500 \mu \mathrm{g}$ / $\mathrm{ml}$ salmon sperm DNA (Sigma), and $0.05 \%$ sodium pyrophosphate. The sections were hybridized for $16 \mathrm{hr}$ at $37^{\circ} \mathrm{C}$ in a similar solution with the following alterations: $100 \mu \mathrm{g} / \mathrm{ml}$ tRNA, $100 \mu \mathrm{g} / \mathrm{ml} \mathrm{DNA}$, and $75,000 \mathrm{cpm} / \mu \mathrm{l}$ of ${ }^{32} \mathrm{P}$-labeled oligonucleotide probe. Nonspecific hybridization of the radiolabeled probe to sections was determined by including a $10 \times$ concentration of unlabeled probe in the prehybridization solution and a $100 \times$ concentration in the hybridization solution. Equivalent amounts of nonspecific hybridization were obtained with a $100 \times$ concentration of unlabeled probe in the prehybridization solution and only labeled probe in the hybridization solution. Following hybridization, sections were washed in $1 \times \mathrm{NTE}, 0.05 \%$ sodium pyrophosphate solution for $20 \mathrm{~min}$ at room temperature followed by $3 \mathrm{hr}$ in a solution containing $10 \mathrm{~mm}$ Tris, $75 \mathrm{~mm} \mathrm{NaCl}$, and $0.05 \%$ pyrophosphate at $37^{\circ} \mathrm{C}$. The sections were then dehydrated with ethanol solutions (5 min each in $50 \%$ ethanol containing $300 \mathrm{~mm}$ ammonium acetate, $70 \%$ ethanol, and $95 \%$ ethanol, and $10 \mathrm{~min}$ in $100 \%$ ethanol). After air drying, the slides were mounted in x-ray cassettes with intensifying screens and exposed to Beta-max hyperfilm (Amersham, Arlington Heights, IL) for $72 \mathrm{hr}$ at $-70^{\circ} \mathrm{C}$. The film was developed in D-19 (Kodak, Rochester, NY) for $5 \mathrm{~min}$ at $18^{\circ} \mathrm{C}$, washed briefly in $1 \%$ acetic acid, and fixed with Kodak Rapid Fixer for $5 \mathrm{~min}$ at $18^{\circ} \mathrm{C}$.

These hybridization experiments were performed two additional times on nearby sections from each brain region of these animals, and similar results were consistently obtained.

Optical density measurements. Optical density (OD) determinations were made using an Amersham RAS/R 1000 Image Analysis System (Loats Associates, Inc., Westminster, MD). Each film contained sections from vehicle- and drug-treated animals. All sections on a single film were hybridized on the same day with the same preparation of radiolabeled probe. To permit comparisons of data from different films, OD measurements from each film were normalized by assigning a value of 1.0 to the OD of the infrapyramidal blade of the dentate granule cell layer to the vehicle-treated animal with the highest absorbance. Mean $O D$ values (total) were obtained for each brain. Nonspecific hybridization values for all of the sections from a film were averaged and subtracted from each total value to determine specific hybridization values. 
Table 1. Relation between seizure indices and seizure-induced c-fos expression in amygdala-stimulated animals

\begin{tabular}{llllll} 
Animal & $\begin{array}{l}\text { Right } \\
\text { amygdala } \\
\text { ADD (sec) }\end{array}$ & $\begin{array}{l}\text { Left } \\
\text { dentate }\end{array}$ & $\begin{array}{l}\text { Forelimb } \\
\text { clonus } \\
(\mathrm{sec})\end{array}$ & $\begin{array}{l}\text { Popula- } \\
\text { tion } \\
\text { spikes/ } \\
\text { seizure }\end{array}$ & $\begin{array}{l}\text { c-fos } \\
\text { mRNA } \\
\left(10^{21}\right. \\
\mathrm{mol} / \\
\left.\mathrm{mm}^{2}\right)\end{array}$ \\
\hline 1 & 122 & 84 & 91 & 139 & 2.1 \\
2 & 81 & $41^{a}$ & 66 & $491^{a}$ & 1.1 \\
3 & 84 & 27 & 65 & 1108 & 2.4 \\
4 & 172 & 143 & 58 & 1140 & 3.5
\end{tabular}

This table presents electrophysiologic and behavioral features of seizures evoked by amygdala stimulation and the seizure-evoked c-fos expression. AD duration (ADD) was recorded from the electrode in the right amygdala and also from the bipolar electrode in the left dentate. The duration of forelimb clonus was determined by behavioral observation. The number of population action potentials was counted in off-line analysis of recorded seizures from three animals as described in Materials and Methods. c-fos mRNA content $\left(10^{-21} \mathrm{~mol} / \mathrm{mm}^{2}\right)$ in the infrapyramidal blade of the left dentate was measured as described in Materials and Methods.

${ }^{a}$ Animal 2 clearly exhibited abundant population action potentials during the final seizure, but technical difficulties precluded tabulation of numbers; this same animal exhibited 491 population action potentials during the $41 \mathrm{sec}$ dentate AD immediately prior to the final one.

\section{Drugs}

Drugs and chemicals were purchased from Sigma Chemical Co., St. Louis, MO, except for MK-801, which was provided by Mcrck, Sharp and Dohme Research Lab, Rahway, NJ, and CGP-37849, which was provided by Ciba-Geigy Ltd., Basel, Switzerland.

Drug doses were based upon studies that documented antagonism of receptor-mediated effects in the CNS after intraperitoneal administration to adult rats. These included antagonists of the NMDA receptor (MK-801; McNamara et al., 1988; Olney et al., 1989), $\beta$-adrenergic receptor (propranolol; Mezey et al., 1983), muscarinic cholinergic receptor (scopolamine; de la Garza et al., 1987), and $\mu$-opiate receptor (naloxone; Cottrell et al., 1988). The doses of CGP-37849 were selected on the basis of our preliminary experiments examining doses effective in inhibiting tonic hindlimb extension of electroshock seizures in rats.

\section{Results}

\section{Correlation of seizure-induced $c$-fos expression in dentate granule cells with dentate field potentials recorded during kindled seizures}

Dentate field potentials were recorded during kindled seizures, the animals were killed $30 \mathrm{~min}$ thereafter, and c-fos expression was examined in the dentate granule cells with in situ hybridization. Stimulation of the amygdala elicited class 5 behavioral seizures and ADs in EEG recordings from the bipolar electrode in the left dentate hilus in all 11 animals. Only 4 of the 11 animals exhibited bursts of population action potentials ("population spikes") in the dentate field potential recordings during the seizures (compare Fig. $1 A, B$ ) (Somjen et al., 1985; Stringer et al., 1991). Robust c-fos mRNA expression was apparent in the dentate granule cells of the left hippocampus in all four of the animals exhibiting bursts of population action potentials and was absent in all seven animals in which population action potentials were not detected during the kindled seizure (Fig. $2 A, B)$. This correlation between the presence of population action potentials during the seizures and c-fos mRNA expression was highly significant (Fisher's exact test, $p=0.002$ ).

Analysis of the electrophysiologic and behavioral features of the seizures among these 11 animals disclosed several interesting features. The duration of the seizures in the group with c-fos expression exceeded the group without c-fos expression [seconds of AD duration (ADD) in the right amygdala, ADD in the left dentate, duration of forelimb clonus, respectively: c-fos present,
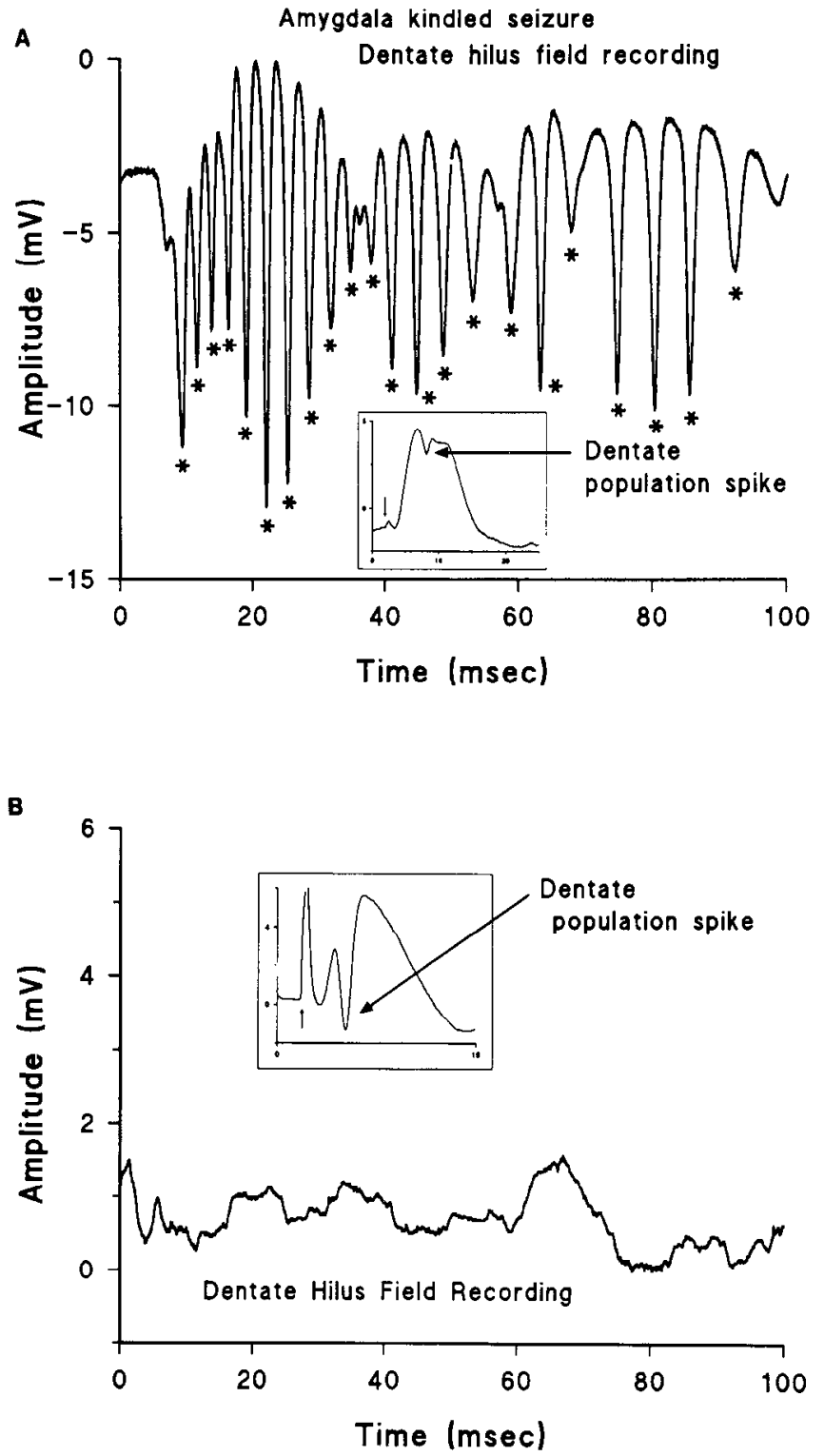

Figure 1. Dentate hilar field potential recordings during seizures evoked by right amygdala stimulation. 'These representative tracings were obtained from an animal exhibiting burst firing of dentate granule cells $(A)$ and an animal without this pattern $(B)$. Both animals exhibited a class 5 seizure with $A D$ durations recorded from the amygdala and dentate, respectively, of $172 \mathrm{sec}$ and $143 \mathrm{sec}(A)$, and $50 \mathrm{sec}$ and $15 \mathrm{sec}$ $(B)$. The insets show the characteristic ungoing EPSP with sharp negative population spike produced by angular bundle stimulation before the seizure was induced (vertical arrows point to stimulation artifact). During part of the kindled seizure, dentate granule cells fire in synchrony as evidenced by multiple population action potentials labeled with asterisks.

$115 \pm 21,74 \pm 26,70 \pm 7 ;$ c-fos absent, $54 \pm 8,45 \pm 10,38$ $\pm 4]$. However, considerable overlap existed between the two groups in that five of the seven animals without c-fos expression exhibited longer AD duration in the left dentate than the shortest AD duration in the left dentate of the group with c-fos expression (27 sec in animal 3, Table 1). The intensity of c-fos mRNA expression varied threefold among the four animals in which c-fos was induced, suggesting that c-fos expression may be a graded response once it reaches a minimal threshold for expression. However, there was no linear relation between the number of population action potentials and the magnitude of 

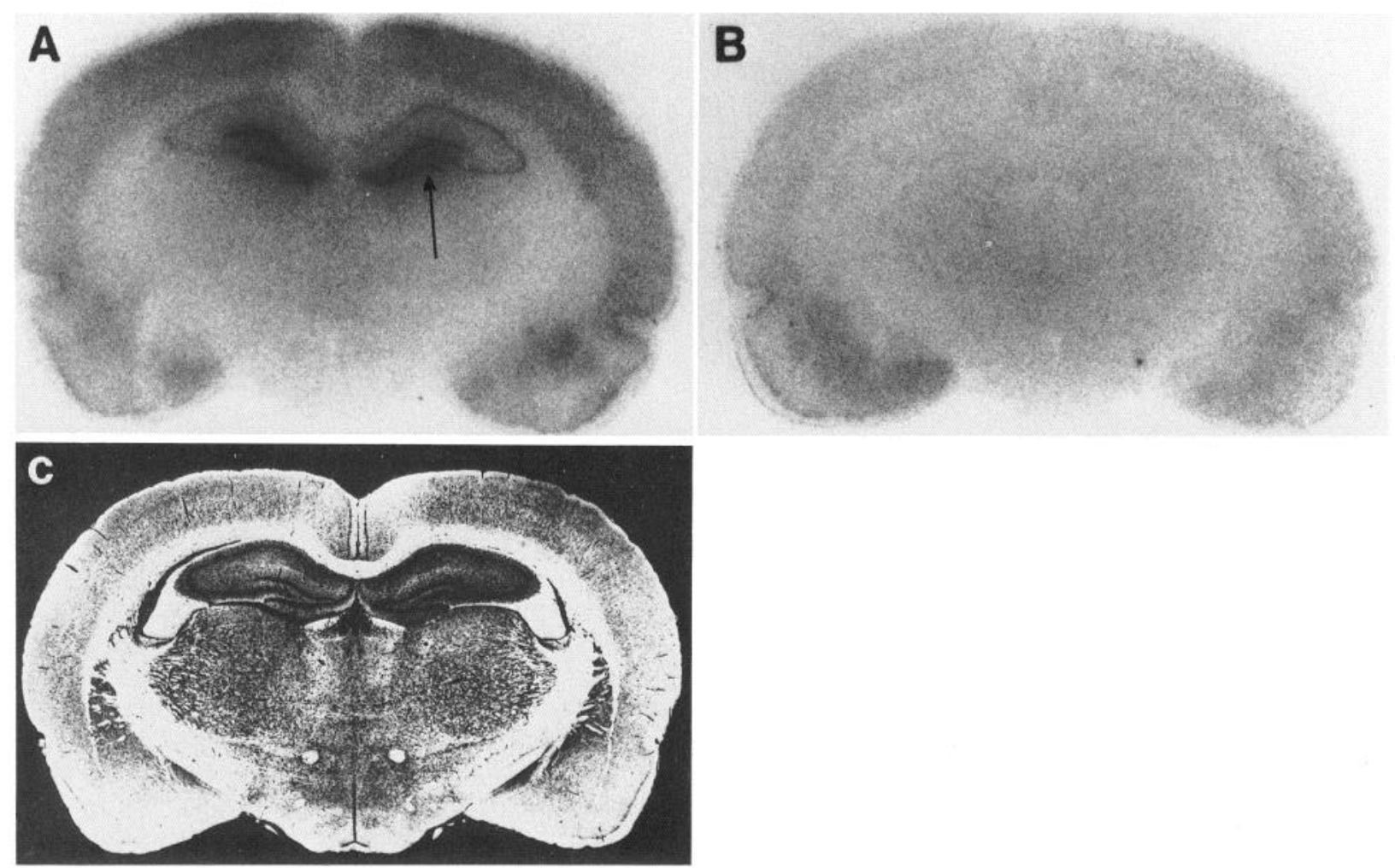

Figure 2. Total binding of oligonucleotide probe (c-fos) to sections of brain from animals portrayed in Figure 1 exhibiting the presence $(A)$ or absence $(B)$ of population action potentials in the left dentate recordings during seizures evoked by right amygdala stimulation. Note the robust c-fos mRNA expression bilaterally in the dentate granule cell layer of the animal presented in $A$, in contrast to the nearly absent expression of c-fos mRNA in the dentate granule cell layer of the animal presented in $B$. Note also the moderate expression of c-fos mRNA in the piriform cortex ipsilateral to the kindling electrode in $B$. Hybridization in the presence of excess unlabeled oligonucleotide, in an adjacent section from the brain used in $A$, resulted in a homogeneous pattern of binding similar to that of $B$ (not shown). $C$ is a Nissl-stained coronal section of rat brain at a level similar to $A$ and $B$. OD measurements were made in the infrapyramidal blade of the dentate granule cell layer as described in Materials and Methods. Scale bar, $5 \mathrm{~mm}$.

c-fos expression, in that nearly equivalent amounts of c-fos mRNA were detected despite a sevenfold difference in number of population action potentials (compare animals 1 and 4 , Table $1)$.

\section{Comparison of kindled seizure-induced c-fos $m R N A$ expression in the dentate gyrus and in the substantia nigra}

Absence of correlation between the number of population action potentials and the magnitude of seizure-induced c-fos mRNA expression in the granule cells led us to examine this relationship in additional populations of neurons. Using both single- and multiple-unit recordings, we had demonstrated the presence of nearly synchronous burst firing of substantia nigra pars reticulata neurons during kindled seizures in 9 of 12 animals (Bonhaus et al., 1986, 1991). We therefore determined whether c-fos mRNA expression was induced in substantia nigra neurons by kindled seizures in a separate group of four animals. To include a positive control internal to these animals, c-fos mRNA expression was measured in the dentate granule cells as well. Three of the four animals exhibited population action potentials in the dentate hilus recordings during the kindled seizures and c-fos mRNA expression in the dentate granule cell layer (Table 2, Fig. 3). The fourth animal exhibited neither population action potentials in the dentate hilus during the kindled seizure nor c-fos mRNA expression in the dentate granule cells. None of these four animals exhibited detectable c-fos mRNA expression in either substantia nigra pars reticulata or pars compacta (Fig. 3). Ad- ditionally, c-fos was not detected in the substantia nigra in any of eight animals following kindled seizures evoked by hippocampal stimulation (vehicle group of Mk-801 experiment, Table 3 ), despite robust expression in the dentate granule cells.

\section{Effects of neurotransmitter receptor antagonists on seizure- induced $c$-fos $m R N A$ expression in dentate granule cells}

To determine whether activation of specific neurotransmitter receptors is required for seizure induction of c-fos mRNA expression, we examined the effects of several receptor antagonists on the seizure-induced c-fos expression. We hypothesized that activation of the NMDA subtype of glutamate receptor during the seizure induced the expression of $\mathrm{c}-$ fos mRNA. The rationale

Table 2. Comparison of c-fos induction in dentate granule cells (DGC) and in substantia nigra (SN)

\begin{tabular}{lllllll} 
Animal & $\begin{array}{l}\text { Clonic } \\
\text { seizure } \\
(\mathrm{sec})\end{array}$ & $\begin{array}{l}\text { Seizure } \\
\text { class }\end{array}$ & $\begin{array}{l}\text { Total } \\
\text { AD } \\
\text { duration } \\
(\mathrm{sec})\end{array}$ & $\begin{array}{l}\text { Popula- } \\
\text { tion } \\
\text { spikes } \\
\text { in DGC }\end{array}$ & $\begin{array}{l}\text { c-fos in } \\
\text { DGC }\end{array}$ & $\begin{array}{l}\text { c-fos in } \\
\text { SN }\end{array}$ \\
\hline 1 & 57 & 5 & 112 & + & + & - \\
3 & 64 & 5 & 134 & + & + & - \\
4 & 49 & 5 & 77 & + & + & - \\
5 & 49 & 5 & 116 & - & - & - \\
\hline
\end{tabular}

+ , Present; -, absent. 
A

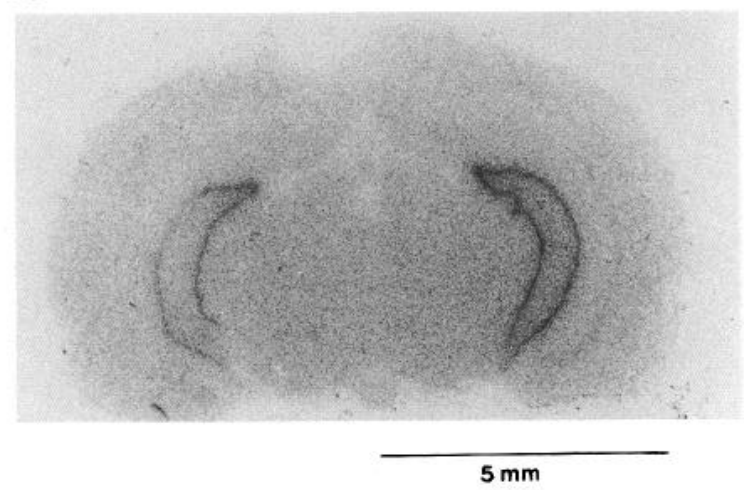

B

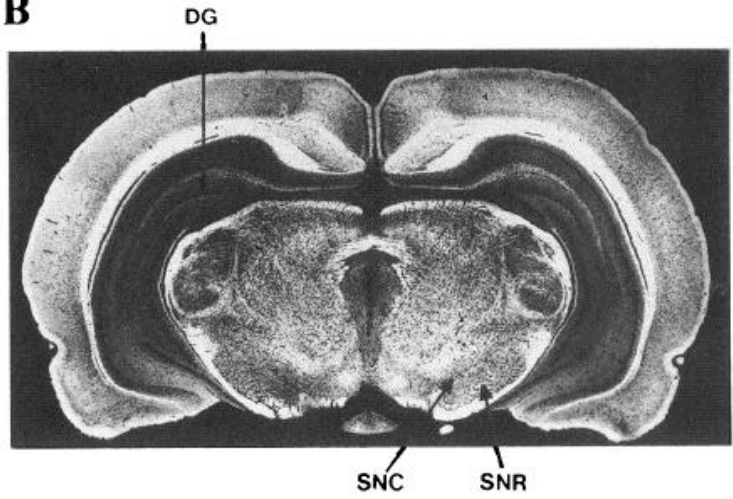

Figure 3. A, Total binding of oligonucleotide probe (c-fos) to coronal section of brain from animal kindled from the right amygdala at the level of substantia nigra and ventral hippocampus. This animal had population action potentials recorded in the dentate hilus in the dorsal hippocampus during the fully kindled seizure. Thirty minutes later, the animal was killed and the brain was isolated and processed for $i n$ situ hybridization. $B$, Nissl-stained section shown for anatomic localization of structures: $D G$, dentate gyrus; $S N C$, substantia nigra pars compacta; $S N R$, substantia nigra pars reticulata. Scale bar, $5 \mathrm{~mm}$.

for this hypothesis was twofold: (1) the principal excitatory afferents of the dentate granule cells from the entorhinal cortex (Andersen et al., 1966; Matthews et al., 1976) use glutamate as a transmitter (White et al., 1977; Keller et al., 1991), and (2) activation of either the $\alpha$-amino-3-hydroxy-5-methylisoxazole4-propionic acid (AMPA) or NMDA subtype of glutamate receptor is sufficient to induce c-fos mRNA expression in isolated dentate gyrus neurons (Lerea et al., 1992).

Pretreatment of animals with CGP-37849, a competitive antagonist of the NMDA subtype of glutamate receptor (Fagg et al., 1990), markedly inhibited the seizure-induced expression of c-fos mRNA. The inhibition was dose dependent, with a 3 $\mathrm{mg} / \mathrm{kg}$ dose producing a $70 \%$ inhibition of c-fos expression contralateral and $66 \%$ ipsilateral to the stimulating electrode (Table 3). Similarly, the uncompetitive NMDA receptor antagonist MK-801 (Wong et al., 1986) reduced seizure-induced expression of c-fos mRNA by approximately $50 \%$ in the dentate granule cells bilaterally (Fig. 4, Table 3). The inhibitory effects of the NMDA receptor antagonists were selective inasmuch as antagonists of $\mu$-opiate (naloxone), muscarinic cholinergic (scopolamine), and $\beta$-adrenergic (propranolol) receptors did not attenuate seizure-induced c-fos mRNA expression (Table 3). Doses of the antagonists used above had been shown to be effective in the CNS (see Materials and Methods).

The possibility that NMDA antagonists inhibited seizure- induced c-fos expression by suppressing seizure duration or seizure-induced bursts of population action potentials of the dentate granule cells was tested electrophysiologically. Pretreatment with MK-801 did not shorten seizure duration recorded on EEG from a hippocampal electrode (ADD: vehicle, $92 \pm 14 \mathrm{sec}$; MK$801,89 \pm 17 \mathrm{sec}$ ), nor did it decrease the number of population action potentials recorded in dentate granule cells during the seizure (Fig. 5). Unexpectedly, MK-801 increased the number of population action potentials recorded in the dentate hilus during seizures in each of four animals studied (number of population action potentials/seizure: vehicle, $297 \pm 114$; MK-801, $849 \pm 80 ; p<0.05)$.

\section{Discussion}

Three principal findings emerge from this study. (1) The occurrence of synchronous firing of dentate granule cells during a seizure correlated with the presence of c-fos mRNA expression in these neurons $30 \mathrm{~min}$ following a seizure. The magnitude of c-fos mRNA expression was not correlated with the number of population action potentials. (2) In the substantia nigra, no induction of c-fos mRNA expression was detected in either pars compacta or pars reticulata neurons, neuronal populations previously demonstrated to exhibit synchronous firing during kindled seizures. (3) Antagonists of the NMDA subtype of gluta-

Table 3. Relative OD values (see Materials and Methods) for c-fos mRNA for vehicle- and drug-treated groups

\begin{tabular}{llllll} 
Drug $(N)$ & $\mathrm{mg} / \mathrm{kg}$ & Ipsilateral vehicle & $\begin{array}{l}\text { Ipsilateral } \\
\text { drug-treated }\end{array}$ & $\begin{array}{l}\text { Contralateral } \\
\text { vehicle }\end{array}$ & $\begin{array}{l}\text { Contralateral } \\
\text { drug-treated }\end{array}$ \\
\hline$(+) \mathrm{MK}-801(8)$ & 1.0 & $0.347 \pm 0.019$ & $0.171 \pm 0.048^{* *}$ & $0.373 \pm 0.021$ & $0.176 \pm 0.051^{*}$ \\
CGP-37849 (5) & 2.0 & $0.392 \pm 0.024$ & $0.383 \pm 0.053$ & $0.370 \pm 0.024$ & $0.329 \pm 0.051$ \\
$\mathrm{CGP}-37849(5)$ & 3.0 & $0.287 \pm 0.031$ & $0.098 \pm 0.027^{*}$ & $0.272 \pm 0.032$ & $0.081 \pm 0.027^{*}$ \\
Naloxone $\cdot \mathrm{HCl}(3)$ & 1.0 & & $0.544 \pm 0.084$ & & $0.441 \pm 0.045$ \\
Scopolamine $\cdot \mathrm{HCl}(3)$ & 2.0 & $0.355 \pm 0.043$ & $0.426 \pm 0.139$ & $0.346 \pm 0.026$ & $0.396 \pm 0.148$ \\
Propranolol $\cdot \mathrm{HCl}(3)$ & 2.5 & & $0.368 \pm 0.109$ & & $0.399 \pm 0.160$ \\
\hline
\end{tabular}

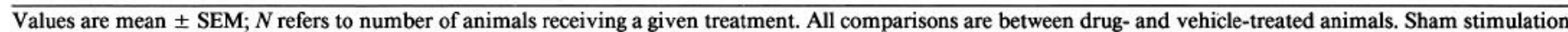

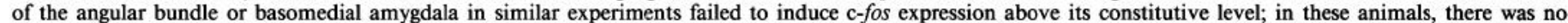
detectable constitutive expression above nonspecific background. * and ** refer to $p<0.01$ and $p<0.05$, respectively (Mann-Whitney $U$ test; Conover, 1980). 

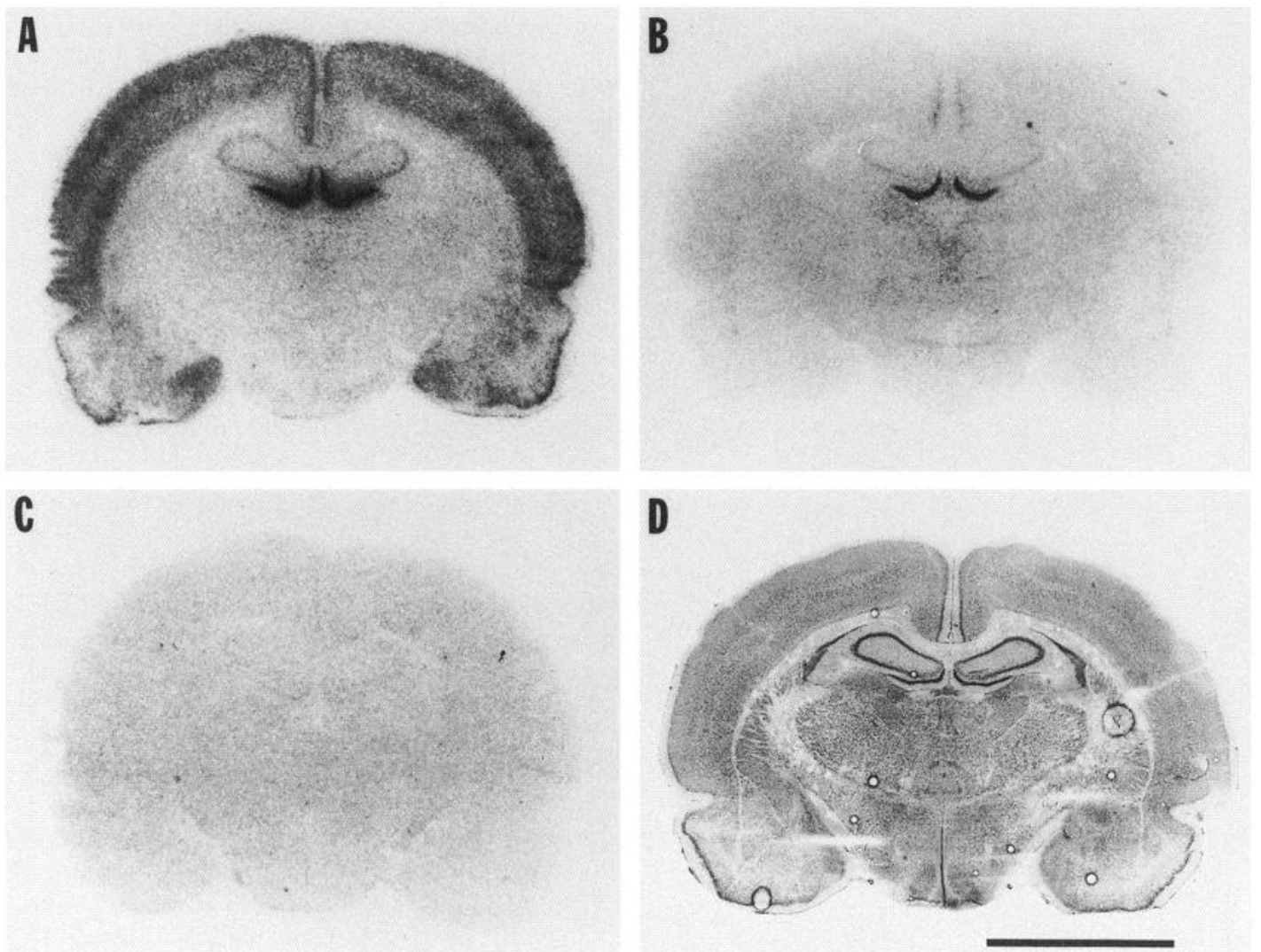

Figure 4. $A$ and $B$, Total binding of oligonucleotide probe (c-fos) to sections of brain from animals pretreated with vehicle $(A)$ or $1.0 \mathrm{mg} / \mathrm{kg} \mathrm{MK}$ $801(B)$ prior to a stimulus-evoked seizure. Seizures evoked by hippocampal stimulation elicited a rapid and dramatic induction of c-fos mRNA bilaterally in the hippocampal formation, pyriform cortex, and layers 3 and $5 / 6$ of neocortex $(A)$. By contrast, the level of constitutive expression of c-fos mRNA in the unstimulated brain was virtually undetectable (not shown). OD measurements of infrapyramidal blade of dentate granule cell layer (in $B$ ) revealed a $60 \%$ reduction in c-fos expression in this MK-801-treated animal compared to the vehicle-treated animal. $C$, Hybridization in the presences of excess unlabeled oligonucleotide, in an adjacent section from the brain used in $A$, resulted in a homogeneous pattern of binding. $D$, Nissl-stained coronal section of rat brain at a level similar to $A-C$. OD measurements were made in the infrapyramidal blade of the dentate granule cell layer as described in Materials and Methods. Scale bar, $5 \mathrm{~mm}$.

mate receptor selectively and markedly inhibited seizure-induced expression of c-fos mRNA in dentate granule cells despite unexpectedly increasing the number of population action potentials by almost threefold.

\section{Validity of $c$-fos $M R N A$ expression as a marker of neuronal burst firing during kindled seizures}

These correlative studies of seizure-induced firing and c-fos mRNA expression illustrate the complexity of the relationship between neuronal activity and the induction of c-fos. Importantly, neuronal activity is defined here as a specific pattern of activity that represents the cellular hallmark of a seizure, namely, the sustained repetitive synchronous firing of populations of neurons (henceforth referred to as epileptiform burst firing). Certainly, c-fos expression is not simply a quantitative or even a qualitative marker of this firing in all CNS neurons. In the dentate granule cells, a striking qualitative correlation was observed between the synchronous firing of granule cells and c-fos mRNA expression; this firing pattern of the dentate granule cells was initially described during kindled seizures by Somjen et al. (1985) and later by Stringer et al. (1991), who coined the term maximal dentate activation for this pattern. However, the epileptiform burst firing was not correlated with seizure induction of c-fos mRNA expression in neurons of the substantia nigra. No detectable c-fos mRNA expression was found in substantia nigra pars compacta or pars reticulata neurons in any of four animals undergoing class 5 kindled seizures evoked by amygdala stimulation or in eight animals by hippocampal stimulation. We previously demonstrated that individual substantial nigra pars compacta and pars reticulata neurons fire in bursts during amygdaloid kindled seizures evoked in five of seven animals in a paralyzed, ventilated preparation (Bonhaus et al., 1986). We confirmed and extended these analyses by demonstrating a nearly synchronous burst firing pattern of populations of substantia nigra pars reticulata neurons in four of five freely moving animals during amygdaloid kindled seizures (Bonhaus et al., 1991). Although the measurements of substantia nigra unit activity and c-fos mRNA expression were not performed in the same animals, it seems likely that c-fos mRNA expression is not induced in substantia nigra neurons despite the presence of epileptiform burst firing during a kindled seizure.

Further complexity is introduced in the dentate granule cells with respect to quantitative considerations in that the magnitude of c-fos mRNA expression, once induced, did not correlate with the number of population action potentials (Table 1). Additionally, as discussed below with hippocampal kindled animals, pretreatment with NMDA receptor antagonists produced a 50 $70 \%$ reduction of seizure-induced c-fos mRNA expression in the dentate granule cells despite a threefold increase of the number of population action potentials. 

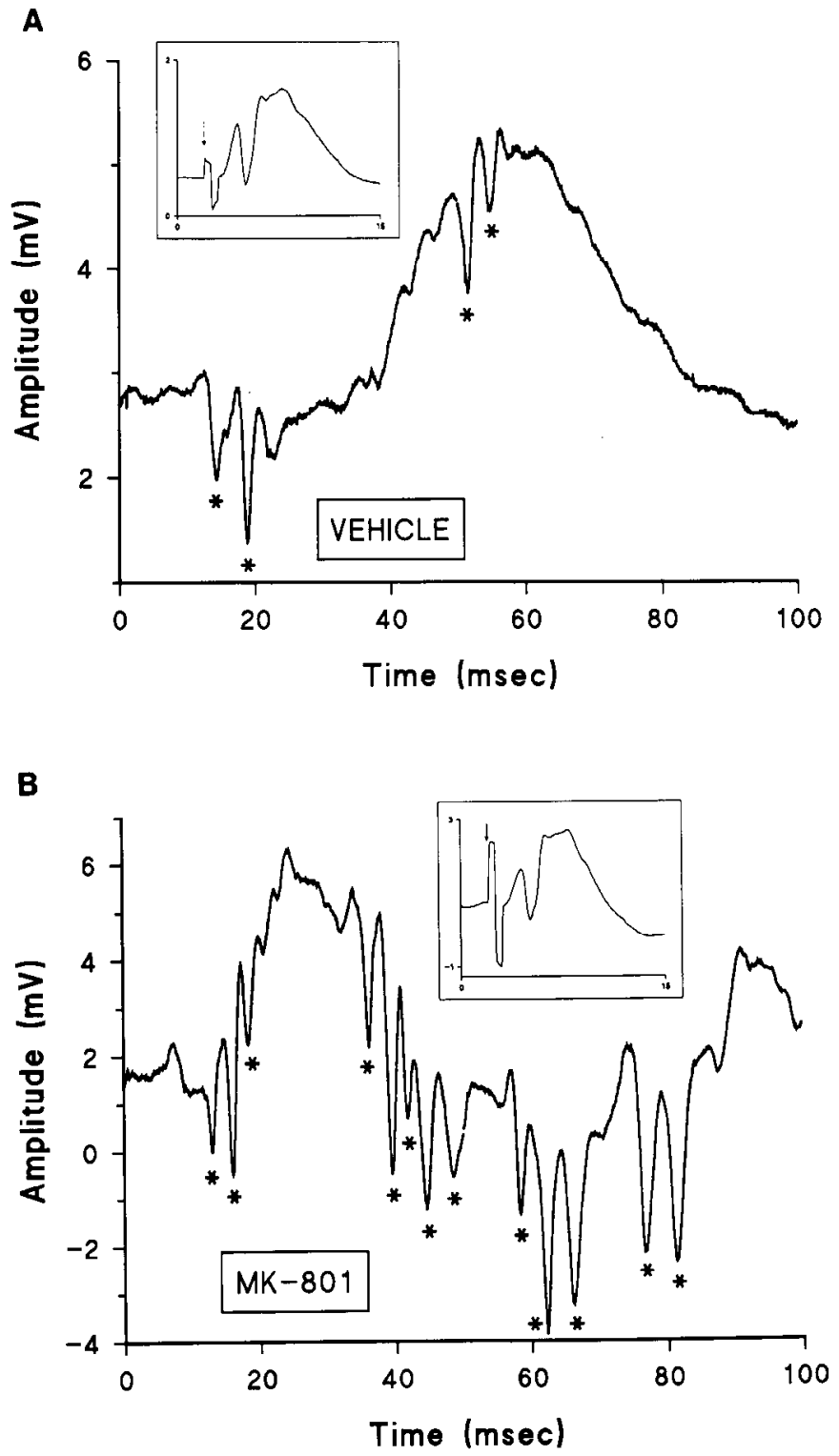

Figure 5. Field potential recordings from the dentate hilus, contralateral to the stimulated hippocampus. In this representative animal, vehicle injection prior to stimulus-evoked seizure $(A)$ was followed 3 weeks later by MK-801 injection prior to stimulus-evoked seizure $(B)$. AD duration was $129 \mathrm{sec}$ and $116 \mathrm{sec}$ during the vehicle-treated and MK801-treated seizures, respectively. The insets show the characteristic upgoing EPSP with sharp negative population spike produced by angular bundle stimulation following administration of vehicle or drug but before the seizure was induced (vertical arrows point to stimulation artifact). During part of the kindled seizure, dentate granule cells fire in synchrony as evidenced by multiple population action potentials labeled with asterisks (number of population action potentials: vehicle, 345 ; MK-801, 991 in this particular cxample). This increase in the number of population action potentials with MK-801 was unexpected, but a previous in vitro study in CA1 may provide some clue (Dingledine et al., 1987). Thus, reduction of the calcium influx by NMDA antagonists may result in reduced activation of calcium-dependent potassium channel, leading to diminished inhibition, explaining at least in part the observed increase in the number of population action potentials.

\section{Mechanisms governing seizure-induced expression of $c$-fos mRNA: a hypothesis}

Understanding the mechanisms by which a seizure induces $\mathrm{c}-$ fos mRNA expression in the dentate granule cells may clarify the relation between c-fos mRNA expression and epileptiform burst firing in other neuronal populations. In vitro studies together with the in vivo studies presented here lead us to suggest that kindled seizures trigger c-fos mRNA expression in the dentate granule cells by the synaptic activation of glutamate receptors on granule cell dendrites, which in turn leads both directly and indirectly to a sustained depolarization and rise of intracellular calcium. Analyses of mechanisms activating c-fos mRNA expression in individual dentate gyrus neurons cultured from 4-dold rat pups and maintained in vitro disclose that activation of either NMDA or AMPA subtypes of glutamate receptors is sufficient to induce robust c-fos mRNA expression; activation of c-fos expression by either receptor requires extracellular calcium (Lerea et al., 1992). Likewise, activation of voltage-sensitive calcium channels by potassium depolarization is sufficient to induce c-fos mRNA expression in a calcium-requiring manner in these neurons. Increases of extracellular glutamate during a seizure (Dodd et al., 1980; Peterson et al., 1983) lead us to suggest that the kindled seizure results in synaptic release of glutamate (White et al., 1977), presumably from entorhinal afferents by virtue of their massive input to the granule cells (Andersen et al., 1966; Matthews et al., 1976), thereby activating both NMDA and AMPA receptors on granule cell dendrites (Keller et al., 1991). Subsequently, as suggested by data from the in vitro study (Lerea et al., 1992), transmembrane flux of $\mathrm{Ca}^{2+}$ through both the NMDA receptor and voltage-activated calcium channels results in an increased concentration of intracellular $\mathrm{Ca}^{2+}$, triggering a signaling cascade that culminates in transcriptional activation of c-fos. The selective inhibition of seizure-induced c-fos mRNA expression by antagonists of NMDA but not three other neurotransmitter receptors is consistent with this interpretation. We suggest that seizure induction of c-fos mRNA may correlate better with sustaincd ncuronal depolarization induced by NMDA receptor activation and other mechanisms than with neuronal burst firing itself. Lack of a straightforward method to measure depolarization of multiple neuronal populations during seizures in awake, freely moving animals precludes direct testing of this idea at present.

This line of reasoning may also provide an explanation for the unexpected increase in the number of population action potentials with MK-801. A previous in vitro study in CA1 using a competitive antagonist, D-aminophosphonovalerate, showed increased number of action potentials in a burst, despite reduced depolarization (Dingledine et al., 1987). The increased number of action potentials may arise from a reduction of calcium influx through the NMDA channel and reduced activation of calciumdependent potassium channels, thereby permitting enhanced sustained firing. Alternatively, the reduction of depolarization may limit sodium channcl inactivation.

We suspect that the residual $30-50 \%$ of c-fos mRNA expression induced by seizures in the presence of NMDA antagonists is due to activation of AMPA receptors and/or activation of voltage-dependent calcium channels, particularly in light of the increased number of population action potentials recorded in the presence of MK-801. The future availability of structurally distinct and highly selective AMPA receptor antagonists that can be administered systemically may allow this possibility to be addressed. We cannot exclude potential contributions from either incomplete blockade of NMDA receptors or activation of the metabotropic subtype of the glutamate receptor, with resultant release of $\mathrm{Ca}^{2+}$ from intracellular stores.

These explanations fail to elucidate why the neurons of the 
substantia nigra do not express c-fos mRNA even though the majority of seizures evoked here are almost certainly associated with an epileptiform burst firing pattern of these neurons. Substantia nigra neurons appear to have the ability to express $c-f o s$, since pentylenetetrazol (PTZ) seizure induced modest Fos-lacZ expression in the substantia nigra in a transgenic mouse strain (Smeyne et al., 1992). Likewise, pilocarpine-evoked status epilepticus is associated with induction of Fos-like immunoreactivity in the substantia nigra (L. E. A. M. Mello, personal communication; Mello et al., 1991). It is possible that seizures evoked by PTZ or pilocarpine activate the neurons of substantia nigra more intensely than a single kindled seizure. Alternatively, these chemically induced seizures may induce c-fos through different mechanisms. Moreover, nigral neurons may have intrinsic properties, such as calcium buffering capacity, distinct from those of dentate granule cells. Further studies of the substantia nigra are needed to explain these differences.

\section{Kindled seizure induction of $c$-fos $m R N A$ expression: implications}

The fact that c-fos mRNA expression is not simply a marker of neuronal activity heightens the importance of elucidating the functional significance of its expression. These findings parallel the complex relationship between the photic induction of c-fos mRNA expression and neuronal activity identified in the suprachiasmatic nucleus of the hypothalamus (Kornhauser et al., 1990). Equivalence in light thresholds and timing of sensitivity of responses suggests that c-fos is a molecular component of the signaling cascade by which light entrains circadian rhythms (Kornhauser et al., 1990). By analogy, c-fos may be a molecular component of the signaling cascade by which seizures induce the lasting hyperexcitability of kindling or the emergence of spontaneous seizures in this model. Circumstantial evidence supports this idea in that two necessary conditions for kindling induction, the occurrence of electrical seizure and activation of NMDA receptors during the seizure, are also necessary for the full expression of c-fos mRNA in the kindling model.

\section{References}

Andersen P, Holmqvist B, Voorhoeve PE (1966) Entorhinal activation of dentate granule cells. Acta Physiol Scand 66:448-460.

Andersen P, Bliss TVP, Skrede KK (1971) Unit analysis of hippocampal population spikes. Exp Brain Res 13:208-221.

Bonhaus DW, Walters JR, McNamara JO (1986) Activation of substantia nigra neurons: role in the propagation of seizures in kindled rats. J Neurosci 6:3024-3030.

Bonhaus DW, Russell RD, McNamara JO (1991) Activation of substantia nigra pars reticulata neurons: role in the initiation and behavioral expression of kindled seizures. Brain Res 545:41-48.

Conover WJ (1980) Practical nonparametric statistics, 2d ed. New York: Wiley.

Cottrell GA, Nyakas C, Bohus B (1988) Hippocampal kindling-induced after-discharge and behavioural depression: immediate and long-term attenuation by opiate antagonists. Eur J Pharmacol 150: $1-8$.

Curran T, Morgan II (1987) Memories of fos. Bioessays 7:255-258.

Curran T, Gordon MB, Rubino KL, Sambucetti LC (1987) Isolation and characterization of the c-fos (rat) $\mathrm{cDNA}$ and analysis of posttranslational modifications in vitro. Oncogene 2:74-87.

de la Garza R, Bickford-Wimer C, Hoffer BJ, Freedman R (1987) Heterogeneity of nicotine actions in the rat cerebellum: an in vivo electrophysiologic study. J Pharmacol Exp Ther 240:689-695.

Dingledine R, Hynes MA, King KL (1986) Involvement of $N$-methylD-aspartate receptors in epileptiform bursting in the rat hippocampal slice. J Physiol (Lond) 380:175-189.
Dodd PR, Bradford HF, Abdul-Ghani AS, Cox DWG, Continho-Netto J (1980) Release of amino acids from chronic epileptic and subepileptic foci in vivo. Brain Res 193:505-517.

Fagg GE, Olpe HR, Pozza MF, Baud J, Steinmann M, Schmutz M, Portet C, Baumann P, Thedinga K. Bittiger H, Allgeier H, Heckendorn R, Angst C, Brundish D, Dingwall JG (1990) CGP 37849 and CGP 39551: novel and potent competitive $N$-methyl-D-aspartate receptor antagonists with oral activity. Br J Pharmacol 99:791-797.

Keller BU, Konnerth A, Yaari Y (1991) Patch clamp analysis of excitatory synaptic currents in granule cells of rat hippocampus. J Physiol (Lond) 435:275-293.

Kornhauser JM, Nelson DE, Mayo KE, Takahashi JS (1990) Photic and circadian regulation of c-fos gene expression in the hamster suprachiasmatic nucleus. Neuron 5:127-134.

Lerea LS, Butler LS, McNamara JO (1992) NMDA and non-NMDA receptor-mediated increase of c-fos mRNA in dentate gyrus neurons involves calcium influx via different routes. J Neurosci 12:2973-2981.

Lomo $T$ (1971) Patterns of activation in a monosynaptic cortical pathway: the perforant path input to the dentate area of the hippocampal formation. Exp Brain Res 12:18-45.

Matthews DA, Cotman C, Lynch G (1976) An electron microscopic study of lesion-induced synaptogenesis in the dentate gyrus of the adult rat. I. Magnitude and time course of degeneration. Brain Res 115:1-21.

McNamara JO, Galloway MT, Rigsbee LC, Shin C (1984) Evidence implicating substantia nigra in regulation of kindled seizure threshold. J Neurosci 4:2410-2417.

McNamara JO, Russell RD, Rigsbee L, Bonhaus DW (1988) Anticonvulsant and antiepileptogenic actions of Mk-801 in the kindling and electroshock models. Neuropharmacology 27:563-568.

Mello LEAM, Tan AM, Finch DM (1991) C-FOS expression in pilocarpine-induced status epilepticus. Soc Neurosci Abstr 17:508.

Mezey E, Reisine TD, Palkovits M, Brownstein MJ, Axelrod J (1983) Direct stimulation of $\beta_{2}$-adrenergic receptors in rat anterior pituitary induces the release of adrenocorticotropin in vivo. Proc Natl Acad Sci USA 80:6728-6731.

Morgan II, Curran T (1986) Role of ion flux in the control of c-fos expression. Nature 322:552-555.

Morgan JI, Curran T (1989) Stimulus-transcription coupling in neurons: role of cellular immediate-early genes. Trends Neurosci 12:459462.

Morgan JI, Cohen DR, Hempstead JL, Curran T (1987) Mapping patterns of c-fos expression in the central nervous system after seizure. Science 237:192-197.

Olney JW, Labruyere J, Price MT (1989) Pathological changes induced in cerebrocortical neurons by phencyclidine and related drugs. Science 244:1360-1362.

Peterson DW, Collins JF, Bradford HF (1983) The kindled amygdala model of epilepsy: anticonvulsant action of amino acid antagonists. Brain Res 275:169-172.

Racine R.I (1972) Modification of seizure activity by electrical stimulation. II. Motor seizure. Electroencephalogr Clin Neurophysiol 32: 281-294.

Sagar SM, Sharp FR, Curran T (1988) Expression of c-fos protein in brain: metabolic mapping at the cellular level. Science 240:13281331.

Shin C, Scialabba FA, McNamara JO (1987) Stimulation of substantia nigra pars reticulata enhances dentate granule cell excitability. Brain Res 411:21-27.

Smeyne RJ, Schilling K, Robertson L, Luk D, Oberdick J, Curran T, Morgan JI (1992) Fos-lacZ transgenic mice: mapping sites of gene induction in the central nervous system. Neuron 8:13-23.

Somjen GG, Aitken PG, Giacchino JL, McNamara JO (1985) Sustained potential shifts and paroxysmal discharges in hippocampal formation. I Neurophysiol 53:1079-1097.

Stringer JL, Williamson JM, Lothman EW (1991) Maximal dentate activation is produced by amygdala stimulation in unanesthetized rats. Brain Res 542:336-342.

White WF, Nadler JV, Hamberger A, Cotman CW, Cummins JT (1977) Glutamate as transmitter of hippocampal perforant path. Nature 270: 356-357.

Wong EHF, Kemp JA, Priestley T, Knight AR, Woodruff GN, Iversen LL (1986) The anticonvulsant Mk-801 is a potent $N$-methyl-Daspartate antagonist. Proc Natl Acad Sci USA 83:7104-7108. 